\title{
CONCEPÇÕES SOBRE OS INSETOS NA LITERATURA DE CORDEL: ESTREITANDO OS LAÇOS ENTRE O CULTURAL E O CIENTÍFICO
}

\author{
CONCEPTIONS ABOUT INSECTS IN CORDEL LITERATURE: THE LINK \\ BETWEEN CULTURAL AND SCIENTIFIC
}

Anderson EDUARDO-SANTOS ${ }^{1}$; Jean Carlos SANTOS²

${ }^{1}$ Graduação em Biologia, Universidade Federal de Sergipe, São Cristóvão, Sergipe, Brasil. agneduardo@gmail.com ${ }^{2}$ Departamento de Ecologia, Universidade Federal de Sergipe, São Cristóvão, Sergipe, Brasil.

\begin{abstract}
RESUMO: Apesar de sua grande importância científica, econômica e epidemiológica, a maioria dos insetos é vista sob uma perspectiva especista, na qual o valor desses animais é medido pelos benefícios ou prejuízos que causam aos humanos. Sabendo disso, o presente estudo teve como principais objetivos analisar as concepções sobre insetos de poetas populares em folhetos de cordéis e avaliar o potencial didático dos folhetos para conteúdos relacionados aos insetos. Para tanto, foi selecionado um corpus de cordéis disponíveis no acervo online da Fundação Casa de Rui Barbosa. Os resultados aqui encontrados demonstram que a ideia de insetos como algo negativo é compartilhada nos folhetos. No entanto, a própria Literatura de Cordel apresenta-se como uma boa alternativa para mudar esse quadro, pois os folhetos também trazem o conhecimento etnobiológico dos autores que pode fazer a aproximação entre cultura e ciência, além de servir como fonte de informação sobre o grupo.
\end{abstract}

PALAVRAS-CHAVE: Entomologia; Cultura; Poesia Popular; Etnobiologia; Ensino de Ciências.

ABSTRACT: Despite their great scientific, economic and epidemiological importance, most insects are seen from a speciesism perspective, in which the value of these animals is measured by the benefits or losses they cause to humans. Knowing this, the present study had as main objectives to analyze the conceptions about insects of popular poets in twine leaflets and to evaluate the didactic potential of the leaflets for contents related to insects. For this purpose, a corpus of twine was selected from the online collection of Fundação Casa de Rui Barbosa. The results found here demonstrate that an idea of insects as something negative is shared in the brochures. However, Cordel Literature itself presents itself as a good alternative to change this situation, since the brochures also bring the biological knowledge of the authors that can bring culture and science together, in addition to serving as a source of information about the group.

KEYWORDS: Entomology; Culture; Popular Poetry; Ethnobiology; Science teaching.

\section{INTRODUÇÃO}

Os insetos formam um dos grupos taxonômicos com maior diversidade e abundância entre os animais no planeta Terra, com mais de um milhão de espécies descritas (ZHANG, 2013; 2020), estima-se que este número possa chegar a 5,5 milhões (STORK, 2018). Eles são essenciais para muitas atividades ligadas ao meio ambiente, tais como a polinização, reciclagem de nutrientes, e ainda servem de alimento para outros animais insetívoros, mantendo a composição e estrutura de diversas comunidades ecológicas terrestres e aquáticas (GULLAN e CRANSTON, 2014; DEL-CLARO e GUILLERMO-FERREIRA, 2019).

É notório que este grupo desempenha funções ecológicas de extrema importância não só para os ecossistemas, mas para os humanos (CULLINEY, 2013; MENTA e REMELLI, 2020; RATCLIFFE et al., 2011; MACADAM e STOCKAN, 2015; NORIEGA et al., 2018). No entanto, há ainda uma ideia bem estabelecida no imaginário popular de que esses organismos são apenas pragas, considerados perigosos, inúteis e repugnantes (COSTA-NETO e PACHECO, 2004).

Outro problema associado aos insetos, principalmente no ensino de Ciências e Biologia, é a dificuldade dos alunos em identificá-los, pois geralmente os confundem com outros invertebrados e até mesmo com alguns vertebrados (COSTA-NETO e MAGALHÃES, 2007). Esse fato pode estar 
relacionado ao atual e ultrapassado modelo de ensino que torna assuntos como este desinteressante para os alunos. Além disso, outro fator a ser levado em consideração são as abordagens nos livros didáticos, os quais, na maioria das vezes, citam apenas os insetos de importância econômica como as pragas agrícolas e vetores de doenças humanas (LABINAS et al., 2010).

Algumas alternativas se mostram bastantes promissoras para amenizar essas problemáticas, uma delas é a aproximação da cultura no ensino de ciências. O resgate do conhecimento cultural do indivíduo, além de desenvolver habilidades artísticas, pode também auxiliar no aprendizado de conteúdos científicos (STRIEDER e STAUB, 2010; SILVIA et al., 2018; SILVEIRA, 2018). Fazendo com que os estudantes reconheçam a importância científica do grupo estudado e que eles entendam a relevância de se preservar a biodiversidade.

Outra alternativa é o resgate do conhecimento etnobiológico do aluno. Neste contexto, a etnobiologia apresenta-se como uma área que tem por objetivo fazer a interlocução do conhecimento proveniente da cultura do aluno com o saber científico (SOUZA e BAPTISTA, 2019).

Nesta perspectiva, os folhetos de cordéis mostram-se uma ferramenta interessante. A Literatura de Cordel é um gênero literário popular que geralmente é escrito de forma rimada e que pode ser divulgado de forma oral ou impresso em folhetos. Bastante disseminado no Brasil, principalmente no Nordeste, onde geralmente são vendidos em feiras por vendedores ambulantes. Os cordéis surgem no país abordando uma grande diversidade de histórias dos mais variados gêneros (ABREU, 1999).

Por apresentar uma linguagem de fácil compreensão e memorização, a Literatura de Cordel se estabeleceu como uma forma de divulgação. Essa característica do gênero pode ser utilizada como recurso didático para disseminação de conteúdos científicos, principalmente aqueles que contêm muitos conceitos complexos, de maneira que os leitores possam assimilar e compreender (BARBOSA et al., 2011; MAYA, 2013; PEREIRA et al., 2014; ROCHAT et al., 2017). Além disso, os folhetos contêm um arcabouço de informações sobre a cultura dos cordelistas (ASSIS, 2012)

Neste sentido, o presente estudo teve por objetivos: (i) analisar folhetos da literatura de cordel, identificando as concepções de poetas populares acerca do grupo dos insetos; e (ii) avaliar o potencial do gênero literário popular como uma ferramenta para o ensino e na divulgação de informações sobre o grupo.

\section{PROCEDIMENTOS METODOLÓGICOS}

Esse estudo parte de uma perspectiva qualitativa. Para tanto, foi utilizado um corpus de folhetos de cordéis, disponíveis no acervo online da Fundação Casa de Rui Barbosa. A instituição é considerada uma das mais importantes do Brasil na área da cultura e preservação de documentos, e possui um grande acervo museológico, além da biblioteca original da casa de Rui Barbosa.

Para consulta foram utilizadas palavras-chave, a saber: "animal", "inseto", "gafanhoto", "grilo", "mosca", "formigas", "besouro", "mariposa" "libélula", "borboleta". Além de termos regionais nordestinos: "lava-bunda", "tanajura", "rola-bosta", "pernilongo", "pirilampo", "serra-pau", "muriçoca" e "mutuca".

Para análise foram utilizados seis folhetos de cordel por trazerem alguma abordagem direta sobre os insetos no corpo do texto. O restante, de maneira geral, aborda diferentes temas como biografias, casamento e natureza. Estes, portanto, na análise foram desconsiderados.

\section{RESULTADOS E DISCUSSÃO}

Como resultado da busca, obtivemos 14 obras de 11 cordelistas, todos de autores homens e naturais de estados do Nordeste, publicados entre os anos de 1937 e 2018 (Tabela 1). Quatro cordéis que apareceram na busca foram escritos pelo poeta cearense Gonçalo Ferreira da Silva, o primeiro e atual presidente da Academia Brasileira de Literatura de Cordel e conhecido por suas obras, principalmente nas áreas da ciência e filosofia.

Quanto às representações dos insetos nos folhetos de cordel, a maioria traz perspectivas negativas acerca do grupo, como no trecho do cordel "Abelhas, morcegos e grilos sugando a humanidade é mesmo de fazer dó".

Além das abelhas os grilos / outra peste acelerada / atacam vilas e cidades / fazendas, sítios, estradas / deixando a humanidade / por devera apavorada. (SOARES e CAMPOS, 1975, p. 1). 
Tabela 1. Resultado da busca dos folhetos. Fonte: Fundação Casa de Rui Barbosa. *Folhetos utilizado para análise neste trabalho.

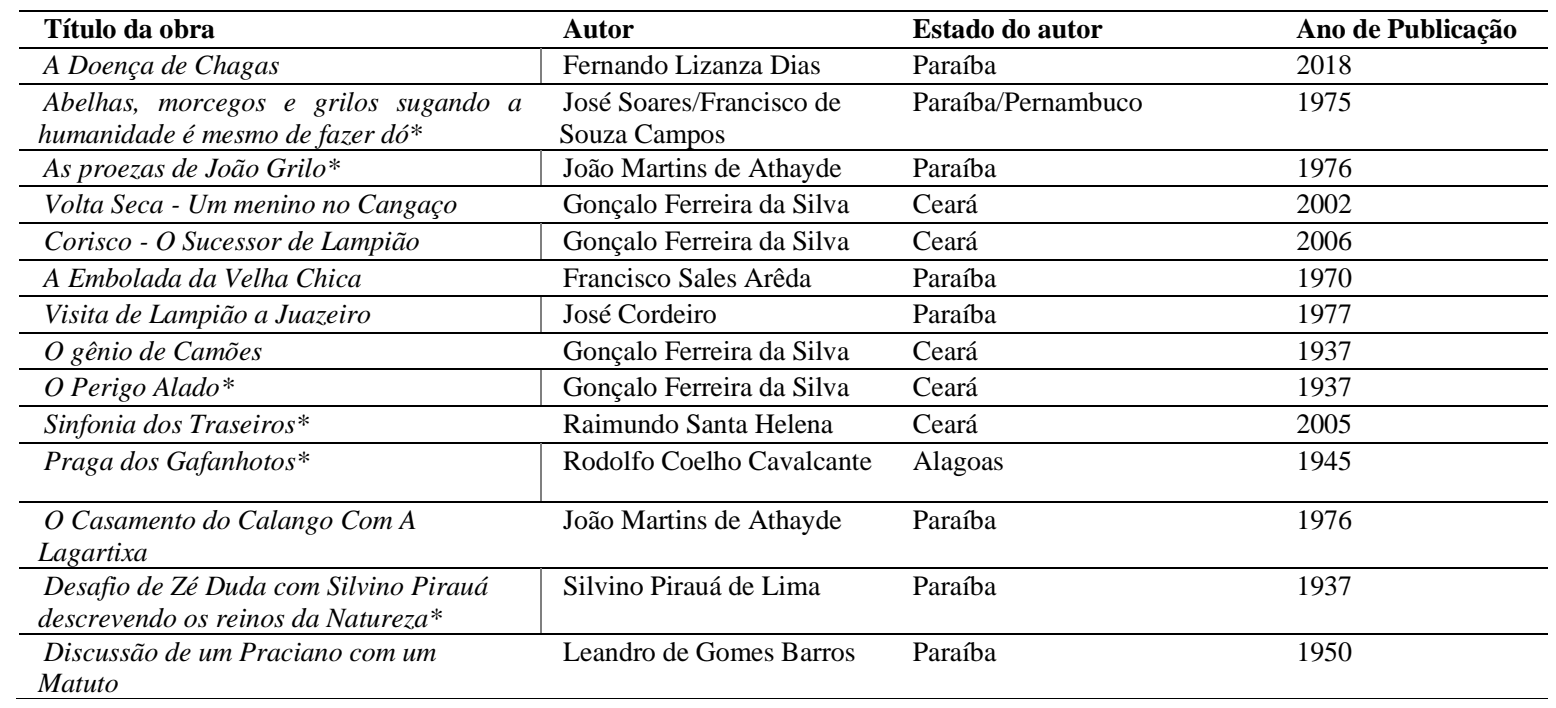

É possível perceber que os autores do cordel acima têm uma visão de que abelhas e grilos são pestes e que causam medo. De acordo com Posey (1986) a percepção dos seres humanos acerca dos insetos está intrinsicamente relacionada à localidade e à cultura em que vivem, e geralmente valores negativos são atribuídos. Até mesmo na comunidade científica, os insetos são vistos de forma nociva e poucos são citados como algo positivo (COSTA-NETO e CARVALHO, 2000). Então, possivelmente, a percepção dos autores citados acima apresenta resquícios culturais adquiridos ao longo de suas vidas. Os trechos a seguir, retirados dos cordéis "Desafio de Zé Duda com Silvino Pirauá descrevendo os reinos da Natureza" e "Praga de Gafanhotos" também evidenciam isso.

Uns gafanhotos terríveis / de ação destruidora / será potência para / "Fortaleza voadora" / Tem garras como dragão / tem cauda como avião / tem dentes como tesoura. (CAVALCANTE, 1945, p. 1).

O gafanhoto a formiga / são de mais perversidade / bicho da seda é talvez / o de mais utilidade / a abelha nos dá o mel / que não tem rivalidade. (LIMA, 1937, p. 12-13).

Para os poetas, gafanhotos e formigas são animais de perversidade, que podem causar algum dano. Provavelmente essa percepção está associada ao fato de que algumas espécies de formigas e gafanhotos são consideradas pragas agrícolas em algumas regiões (ALVES et al., 2015). Lima (1937) cita ainda o bicho-da-seda e as abelhas e atribui certo valor, fazendo referência à importância econômica desses animais. As abelhas produzem o mel e a própolis, produtos de interesse humano. O bicho-da-seda é outro inseto economicamente importante, pois produz a seda - matéria prima utilizada na indústria têxtil. Os efeitos negativos dos insetos na agricultura ainda são evidenciados em outro trecho do mesmo cordel, no qual o autor questiona a importância do grupo.

Sobre a classe dos insectos / responda-me, agora, então / quais os que mais estragam / a lavoura ou a plantação / se existem insectos úteis / me explique agora quais são. (LIMA, 1937, p. 12-13).

Segundo Bomfim et. al. (2016) a aparência "desagradável" de alguns desses animais também pode ser um motivo que influencia na percepção negativa que a sociedade tem sobre eles. Além disso, o trabalho destes autores evidencia que as pessoas se sentem incomodadas com a presença de insetos em suas casas, pois temem a transmissão de doenças. Essa percepção também é compartilhada pelo poeta Gonçalo Ferreira da Silva, em um trecho do seu cordel intitulado "O Perigo Alado". 
A frase de Atthayde / merece ser repetida: "/ um mosquito pica um homem / disso vira uma ferida / da ferida o homem morre / tirou-lhe o mosquito a vida". (SILVA, 1937, p. 1).

Longo e Pires (1998) argumentam que os grandes meios de comunicação também têm um papel fundamental no que diz respeito à transmissão de informações sobre os insetos, entretanto, de maneira geral, disseminam sempre uma conotação negativa acerca do grupo. O que não parece ser diferente nos pequenos e restritos veículos de comunicação, como a Literatura de Cordel.

Contudo, apesar da maioria dos folhetos trazer essa conotação negativa sobre o grupo, isso não tira ou neutraliza a potencialidade didática dos cordéis, principalmente no ensino de ciências, uma vez que eles podem ser utilizados em aulas sob uma perspectiva crítica, através da problematização. Os alunos também apresentam concepções prévias sobre determinados assuntos e através da problematização, estes podem adquirir novos significados e sentidos, desde que as relações com o objeto de estudo sejam mantidas (HALMENSCHLAGER, 2011).

Um estudo realizado por Almeida et al. (2016) sobre as representações da ciência e da tecnologia na literatura de cordel, mostrou que essas convergências entre o conhecimento científico e conhecimento popular na literatura de cordel são uma ferramenta que tem potencial na disseminação de conteúdos científicos e na aproximação do conhecimento popular com a ciência.

Isso é evidenciando em trechos do cordel "Proezas de João grilo", no qual o autor aborda o conhecimento popular acerca do grupo dos vagalumes (Coleoptera: Elateroidea: Lampyridae; Phengodidae, Elateridae), conhecidos pela produção natural de luz.

João, qual é o bicho / que passa pela campina / a qualquer hora da noite / andando de lamparina? / é um pequeno animal/ tem luz artificial/ veja o que determina.

Esse bicho eu já vi / pois eu tinha por costume / de brincar sempre com ele / minha mãe tinha ciúme / ele andava pelo campo / uns chamavam pririlampo / e outros de vagalume. (ATHAYDE, 1976, p. 21).

O etnoconhecimento também é visto em trechos do cordel "Sinfonia dos traseiros", em que o autor fala sobre a produção de sons pelas cigarras (Hemiptera: Cicadidae). Os sons que as cigarras emitem são produzidos pelo tímbalo, um órgão presente apenas no abdômen do macho e essa emissão está associada principalmente ao acasalamento desses animais. (BENNET-CLARCK e YOUNG, 1992; BOULARD, 2006).

Respeito qualquer traseiro / E nem penso no da Santa / Dos Besouros tenho medo/ Pois com seu ferrão espanta - / Quando ferroa agarra. / E coitada da cigarra, /Que pelo traseiro canta...

Traseiro de Tanajura / Já comi hoje não como: / É a formiga saúva / A rainha-cromossomo / Até hoje quando pica / Nosso corpo de dor quica / Que nem os pés do Rei Momo. (HELENA, 2005, p. 3-4).

Helena ainda faz menção às formigas do gênero Atta, dizendo que as utilizava na alimentação. Muitas comunidades utilizam partes dessas formigas, principalmente o abdômen, como fonte de alimento, pois esses animais apresentam um alto valor nutricional (COSTA-NETO, 2000; 2003; MELO, 2015). Notase, portanto, que os poetas supracitados expõem saberes tradicionais sobre os insetos adquiridos em seu entorno cultural. Essas informações podem ser utilizadas em aulas de ciências e biologia, uma vez que os alunos também trazem uma bagagem cultural que poderia somar na construção de novos conhecimentos acerca do grupo. Lima e Sovierzoski (2019), por exemplo, realizaram um estudo com estudantes do ensino fundamental, utilizando a Literatura de Cordel como ferramenta para o ensino conteúdos sobre invertebrados marinhos. As autoras argumentam que o gênero literário popular foi um dos fatores predominantes na aprendizagem, pois ele valoriza o conhecimento etnobiológico dos estudantes, o que aumenta o interesse pelo assunto. O enfoque etnobiológico no ensino, além de fazer a aproximação do conhecimento cultural com o científico, também auxilia na formação de professores 
mais sensíveis à diversidade cultural e contribui para que eles reflitam sobre práticas pedagógicas mais inclusivas (BAPTISTA, 2015).

Além de trazer o conhecimento popular em seus versos, os cordéis contêm informações científicas que poderiam ser utilizadas na sensibilização sobre temas pertinentes, como é o caso dos trechos a seguir, retirados do folheto "O Perigo Alado".

E o mosquito do dengue- / Particular criatura - / Vive menos de um mês / Não atinge grande altura / E não suporta nem alta / Nem baixa temperatura.

[...] Para o mosquito do dengue / O local mais indicado / É um corpo de água limpa / Em local claro deixado / É um hotel cinco estrelas / Pelos deuses instalado.

[...] Não deixar água parada / em panelas, em banheiro / em pneus, cacos de coco / em vaso exposto em terreiro / em sacadas, nas escadas / vigilância o dia inteiro.

Não sabemos se o mosquito / Descrito na frase prima / Era o que provoca o dengue / Que ama o tropical clima / Mas já provocou estragos / Como se percebe acima. (SILVA, 1937, p. 2-4).

Nos versos, o autor aborda tanto a biologia e a ecologia do mosquito Aedes aegypti, vetor de diferentes arboviroses, como também faz uma alerta para os locais de foco do mosquito, numa linguagem bem mais acessível. Essas informações poderiam ser úteis não só no âmbito acadêmico, mas também para população em geral, como em campanhas que têm como objetivo conscientizar sobre o controle do mosquito e o combate de doenças causadas por ele. Essa característica do gênero de abordar diferentes assuntos de forma rimada, mostra que os cordéis têm potencial didático, podendo contribuir no aprendizado de diferentes temas.

\section{CONSIDERAÇÕES FINAIS}

Os resultados aqui apresentados vão ao encontro com outros estudos que buscaram compreender questões acerca da percepção humana sobre os insetos. Estes estudos sugerem que essas concepções muitas vezes levam em consideração apenas a perspectiva humana, ignorando a importância ecológica desses animais. Muitas dessas concepções negativas também são compartilhadas por poetas populares em seus cordéis. Entretanto, é importante considerar que os folhetos de cordel têm um papel muito importante no que diz respeito à transmissão de informações e conhecimento, sobretudo o popular, no Nordeste. Além disso, o etnoconhecimento apresentado pelos poetas acerca dos insetos, desde que sejam analisados sob uma perspectiva crítica e construtiva, pode contribuir em aulas de ciências, ajudando na formação de professores que levam em consideração a diversidade cultural dos alunos, e alunos mais interessados em aprender ciência. Apesar de não haver trabalhos na literatura que abordem a utilização de cordéis no ensino e na divulgação científica de insetos, esta pode ser uma ferramenta muito eficaz no processo de ensino-aprendizagem do grupo, que vem sendo negligenciado há anos. É importante, portanto, que mais trabalhos como este sejam desenvolvidos, analisando as mensagens veiculadas nos folhetos, mas que não fique restrito a isso. Professores e cientistas podem utilizar a Literatura de Cordel - produzindo novos folhetos - para disseminar informações sobre o grupo, não só em aulas de ciências, mas para população em geral.

\section{REFERÊNCIAS}

ALMEIDA, Carla; MASSARANI, Luisa; MOREIRA, Ildeu de Castro. Representações da ciência e da tecnologia na literatura de cordel. Bakhtiniana: Revista de Estudos do Discurso, v. 11, n. 3, p. 5-25, 2016.

ALVES, Maria Teresa Albuquerque; FREIRE, Joaquim Evando; BRAGA, Petronio Emanuel Timbó. O conhecimento local sobre os insetos pelos moradores do município de Groaíras, Ceará. Ensaios e Ciência: Ciências Biológicas, Agrárias e da Saúde, v. 19, n. 1, p. 7-15, 2015.

ASSIS, Regiane Alves de; TENÓRIO, Carolina Martins; CALLEGARO, Tânia. Literatura de cordel como fonte de informação. CRB-8 Digital, v. 5, n. 1, p. 3-21, 2012.

BAPTISTA, Geilsa Costa Santos. Um enfoque etnobiológico na formação do professor de ciências sensível à diversidade cultural: estudo de caso. Ciência \& Educação (Bauru), v. 21, n. 3, p. 585-603, 2015.

BARBOSA, Alex Samyr Mesquita; PASSOS, Carmensita Matos Braga; COELHO, A. de A. O cordel como recurso didático no ensino de ciências. Experiência em Ensino de Ciência, v. 6, n. 2, p. 161-168, 2011. 
BENNET-CLARK, Henry C.; YOUNG, D. A model of the mechanism of sound production in cicadas. Journal of Experimental Biology, v. 173, n. 1, p. 123-153, 1992.

BOMFIM, Brunna Laryelle Silva et al. Etnoentomologia em comunidade rural do cerrado piauiense. Desenvolvimento e Meio Ambiente, v. 39, 2016.

COSTA-NETO, Eraldo M.; MAGALHÃES, Henrique. The ethnocategory"insect"in the conception of the inhabitants of Tapera County, São Gonçalo dos Campos, Bahia, Brazil. Anais da Academia Brasileira de Ciências, v. 79, n. 2, p. 239-249, 2007.

COSTA-NETO, Eraldo Medeiros. Conhecimento e usos tradicionais de recursos faunísticos por uma comunidade afro-brasileira. Resultados preliminares. Interciencia, v. 25, n. 9, p. 423-431, 2000.

COSTA-NETO, Eraldo Medeiros. Insetos como fontes de alimentos para o homem: valoração de recursos considerados repugnantes. Interciencia, v. 28, n. 3, p. 136-140, 2003.

COSTA-NETO, Eraldo Medeiros; CARVALHO, Paula. Percepção dos insetos pelos graduandos da Universidade Estadual de Feira de Santana, Bahia, Brasil. Acta Scientiarum. Biological Sciences, v. 22, p. 423$428,2000$.

COSTA-NETO, Eraldo Medeiros Costa; PACHECO, Josué Marques. A construção do domínio etnozoológico "inseto" pelos moradores do povoado de Pedra Branca, Santa Terezinha, Estado da Bahia. Acta Scientiarum. Biological Sciences, v. 26, n. 1, p. 81-90, 2004.

CULLINEY, Thomas. Role of arthropods in maintaining soil fertility. Agriculture, v. 3, n. 4, p. 629-659, 2013

DEL-CLARO, Kleber. GUILlERMO-FERREIRA, Rhainer. Aquatic Insects. Behavior and Ecology. Springer, Cham. 2019.

GULLAN, Penny J.; CRANSTON, Peter S. The insects: an outline of entomology. John Wiley \& Sons, 2014.

HALMENSCHLAGER, Karine Raquel. Problematização no Ensino de Ciências: uma análise da Situação

de Estudo. VIII Encontro Nacional de Pesquisadores em Ensino de Ciências, 1-12. 2011. Campinas.

LABINAS, Adriana Mascarette; CALIL, Ana Maria Gimenes Corrêa; AOYAMA, Elisa Mitusko. Experiências concretas como recurso para o ensino sobre insetos. Revista Ciências Humanas, v. 3, n. 1, p. 96-103. 2010

MACADAM, Craig R.; STOCKAN, Jenni A. More than just fish food: ecosystem services provided by freshwater insects. Ecological Entomology, v. 40, p. 113-123, 2015.

MELO, Ana Carolina Brasileiro et al. O conhecimento popular acerca dos insetos no município de Cariré, Ceará, Brasil. Ciência e Natura, v. 37, n. 2, p. 253-260, 2015.

MENTA, Cristina; REMELLI, Sara. Soil Health and Arthropods: From Complex System to Worthwhile Investigation. Insects, v. 11, n. 1, p. 54, 2020.

NORIEGA, Jorge Ari et al. Research trends in ecosystem services provided by insects. Basic and Applied Ecology, v. 26, p. 8-23, 2018.

PEREIRA, Lívia Maria Galdino et al. O cordel no ensino de microbiologia: a cultura popular como ferramenta pedagógica no ensino superior. Revista Eletrônica de Comunicação, Informação e Inovação em Saúde, v. 8, n. 4, 2014

POSEY, Darrel. Tópicos e inquirições em etnoentomologia: algumas sugestões quanto á geração e teste de hipóteses. Boletim Museu Paranaense Emílio Göeldi, Série Antropologia, v.3, n.2, p.99-134, 1987.

RATCLIFFE, Norman A. et al. Insect natural products and processes: new treatments for human disease. Insect biochemistry and molecular biology, v. 41, n. 10, p. 747-769, 2011.

ROCHA, Jorge Manso et al. Educação Ambiental No Combate Ao Comércio Ilegal Da Avifauna Silvestre Em Sergipe. Ethnoscientia, v. 2, n. 1, 2017.

SILVEIRA, João Ricardo Aguiar da. Arte e Ciência: uma reconexão entre as áreas. Ciência e Cultura, v. 70, n. 2, p. 23-25, 2018.

SOUZA, Maria Laura Souza.;BAPTISTA, Geilsa Costa Santos. Conhecimento tradicional como instrumento para dinamização do currículo e ensino de ciências. Gaia Scientia, v. 12, n. 4, 21 jan. 2019.

STORK, Nigel E. How many species of insects and other terrestrial arthropods are there on Earth?. Annual review of entomology, v. 63, p. 31-45, 2018.

ZHANG, Zhi-Qiang. Animal biodiversity: An outline of higher-level classification and survey of taxonomic richness. p.1-25. Magnolia press, 2011. 